УДК 911.37(470.341)

ИЗУЧЕНИЕ ДЕМОГРАФИЧЕСКИХ АСПЕКТОВ МАЯТНИКОВОЙ МИГРАЦИИ НАСЕЛЕНИЯ НИЖЕГОРОДСКОЙ ОБЛАСТИ

'Шевченко И.А., ${ }^{1}$ Давыдова Ю.В., 'Замашкина О.В., 'Зарубина Н.В.,

${ }^{2}$ Лябина А.Н., ${ }^{2}$ Бикмаева А.В.

${ }^{\prime}$ ФГБОУ ВО «Нижегородский государственный педагогический университет имени К. Минина», Нижний Новгород, е-mail: irina-dzr52@mail.ru;

${ }^{2}$ ФБОУ ВО «Российская академия народного хозяйства и государственной службы при Президенте РФ», Дзержинский филиал, Москва

В статье рассмотрена актуальная проблема выявления особенности демографических аспектов маятниковой миграции населения Нижегородской области. Постоянный приток социально активного населения в пригородную зону Нижнего Новгорода, а также развитие транспортной и инженерной инфраструктур областного центра приводили к тому, что не всегда новые специализированные участки и филиалы промышленного комплекса Нижнего Новгорода строились в тех городах, где это считалось целесообразным. Многие хозяйственные объекты размещаются вблизи городской черты, стимулируя здесь ускоренный рост и агломерацию поселений. Развитие такого процесса стимулирует маятниковую миграцию сельского населения и дополняет ее все возрастающими потоками межгородских маятниковых передвижений. Благодаря развитию маятниковой миграции часть необходимой городам рабочей силы привлекается из окружающей городских и сельских поселений. Особенно велико ее значение для социально-экономического развития такого города, как Нижний Новгород. здесь маятниковая миграция выполняет двойную роль: с одной стороны, она регулирует рост численности населения этого города; с другой - пополняет недостающие трудовые ресурсы. Маятниковая миграция охватывает все более значительные слои населения, возрастает ее роль в жизни общества. Сделана попытка изучения маятниковой миграции как современной черты сельского образа жизни. Нашли свое дальнейшее развитие социальные аспекты в изучении маятниковой миграции населения. Процессы формирования новых центров социально-экономического развития области и становления агломерации в окружении Нижнего Новгорода развиваются одновременно. Материалы статьи представляют практическую ценность, поскольку дальнейшее развитие маятниковой миграции во многом зависит от того, какому из этих процессов будет отдано предпочтение в перспективной организации территориально-хозяйственного комплекса города.

Ключевые слова: демография, миграция, маятниковая миграция, социальный портрет, маятниковый мигрант, образ жизни, население

\title{
THE STUDY OF DEMOGRAPHIC ASPECTS OF CIRCULAR MIGRATION OF THE POPULATION OF NIZHNY NOVGOROD REGION
}

\author{
${ }^{1}$ Shevchenko I.A., ${ }^{1}$ Davydova Yu.V., ${ }^{1}$ Zamashkina O.V., ${ }^{1}$ Zarubina N.V., \\ ${ }^{2}$ Lyabina A.N., ${ }^{2}$ Bikmaeva A.V. \\ ${ }^{1}$ Nizhny Novgorod State Pedagogical University named after K. Minin, \\ Nizhny Novgorod, e-mail: irina-dzr52@mail.ru; \\ ${ }^{2}$ The Russian Presidential Academy of National Economy and Public Administration, Moscow
}

The article deals with the actual problem of identifying the features of demographic aspects of the pendulum migration of the population of the Nizhny Novgorod region. The constant influx of socially active population in the suburban area of Nizhny Novgorod, as well as the development of transport and engineering infrastructure of the regional center led to the fact that not always new specialized sites and branches of the industrial complex of Nizhny Novgorod were built in those cities where it was considered appropriate. Many economic facilities are located near the city limits, stimulating the accelerated growth and agglomeration of settlements. The development of such a process stimulates the pendulum migration of the rural population and complements it with increasing flows between urban pendulum movements. Thanks to the development of pendulum migration, part of the labor force needed by cities is attracted from the surrounding urban and rural settlements. as a source of labor, pendulum migration does not directly lead to the growth of the city's population. especially great is its importance for the socio-economic development of such a city as Nizhny Novgorod. here, pendulum migration plays a dual role: on the one hand, it regulates the growth of the population of this city; on the other, it replenishes the undersupplied labor resources. Pendulum migration covers more and more significant segments of the population, its role in the life of society increases. An attempt is made to study pendulum migration as a modern feature of rural lifestyle. Social aspects found their further development in the study of pendulum migration of the population. The processes of formation of new centers of socio-economic development of the region and the formation of agglomeration in the environment of Nizhny Novgorod are developing simultaneously. The materials of the article are of practical value, since the further development of pendulum migration largely depends on which of these processes will be preferred in the perspective organization of the territorial and economic complex of the city.

Keywords: demographics, migration, pendulum migration, social portrait, pendulum migrant, lifestyle, population

Закономерное ограничение роста крупнейших городских агломераций вызывает привлечение трудовых ресурсов из пригородной зоны через маятниковые миграции, или поездки. В этих поездках участвуют не только жители городов и поселков городского типа, но и жители сельских поселений, расположенных близ транспортных 
магистралей, надежно связывающих ядро агломерации с периферийными участками. Как правило, удельный вес маятниковых мигрантов в пригородных сельских поселениях ниже, чем в городских поселениях, поскольку часть трудоспособного населения сел продолжает заниматься сельским хозяйством. Тем не менее трудовые поездки достаточно значительны, чтобы заниматься изучением их структуры, взаимодействия с демографической ситуацией и условиями их развития [1].

Цель исследования: выявление особенности демографических аспектов маятниковой миграции населения Нижегородской области. Постоянный приток социально активного населения в пригородную зону Нижнего Новгорода, а также развитие транспортной и инженерной инфраструктур областного центра приводили к тому, что не всегда новые специализированные участки и филиалы промышленного комплекса Нижнего Новгорода строились в тех городах, где это считалось целесообразным. Многие хозяйственные объекты размещаются вблизи городской черты, стимулируя здесь ускоренный рост и агломерацию поселений. Развитие такого процесса стимулирует маятниковую миграцию сельского населения и дополняет ее все возрастающими потоками межгородских маятниковых передвижений. Благодаря развитию маятниковой миграции часть необходимой городам рабочей силы привлекается из окружающих городских и сельских поселений. Особенно велико ее значение для социально-экономического развития такого города, как Нижний Новгород. здесь маятниковая миграция выполняет двойную роль: с одной стороны, она регулирует рост численности населения этого города; с другой - пополняет недостающие трудовые ресурсы.

\section{Материалы и методы исследования}

В процессе исследования нами были рассмотрены миграционные процессы Нижегородской области. Методы исследования: анализ литературы; картографический; описательный; геоинформационный; статистический; географического районирования. Наибольшее влияние на интенсивность трудовой маятниковой миграции оказывает величина городских поселений, уровень индустриального развития, их транспортная и временная доступность. Каков же социальный портрет маятникового мигранта? В числе работающих в городах, как отмечено ранее, основную массу представляют женщины $(57 \%)$. Это объясняется особыми условиями женского труда в сельском хозяйстве, строительстве и промышленности на селе [2]. Социология установили четкую закономерность, что именно неудовлетворительные условия труда на местах проживания вынуждают женщин работать в городах. По мере роста на селе рабочих мест с удовлетворительными условиями труда удельный вес женщин в числе работающих в городах должен сокращаться. Так оно и происходит фактически. Об этом свидетельствует сокращение удельного веса женщин-мигрантов с $65 \%$ до $57 \%$. За последние годы произошли прогрессивные изменения в квалифицированно-должностной и профессионально-отраслевой структурах сельских работников, главным образом женщин [3].

Для маятниковых мигрантов, как мужчин, так и женщин, характерно преобладание молодежи по сравнению с другими работниками (17-30 лет). Следовательно, город притягивает к себе дефицитную на селе квалифицированную рабочую силу, поскольку уровень образования молодежи выше. В самом деле, среди сельских жителей, работающих в городах, каждый десятый имеет высшее или среднее специальное образование, каждый третий окончил курсы повышения квалификации или был подготовлен по новой профессии, каждый пятый закончил техникум или колледж. В числе маятниковых мигрантов лиц с полным средним общим образованием в 2 раза больше, чем среди работающих на селе. Поскольку в городах работают и люди старших возрастов, среди них есть работники с неполным общим средним образованием (почти половина всех мужчин) и даже с начальным (7\% всех работающих в городах). Среди работающих в городах выделяется группа мужчин 40-47 лет и женщин первого пятилетия после пенсионного возраста. Уровень образования маятниковых мигрантов позволяет им работать по самым разнообразным специальностям [4].

\section{Результаты исследования и их обсуждение}

В результате выборочного обследования маятниковых мигрантов Нижегородской области были получены следующие результаты. Во-первых, бросается в глаза, что маятниковые мигранты занимают рабочие места всех рангов. Однако в их числе в 2 раза меньше руководителей и специалистов и в 3 раза больше служащих-неспециали- 
стов, чем у работающих на селе. Во-вторых, за пять лет в их социальном статусе, как и в составе всех работающих на селе, произошли существенные сдвиги в сторону сокращения занятых неквалифицированным трудом и увеличения удельного веса служащих-неспециалистов. Небольшой удельный вес высококвалифицированных работников среди мигрантов - результат проводимой работы на селе по дополнительному стимулированию дефицитного труда специалистов непосредственно в сельском хозяйстве (введение ряда льгот и привилегий).

Исследование маятниковых мигрантов по отраслям народного хозяйства Нижнего Новгорода в последние годы показало, что среди приезжающих преобладают мигранты, занятые в отраслях материального производства (79\%). При этом почти половина маятниковых мигрантов (45\%) занята в промышленности. В числе трудовых маятниковых мигрантов преобладают рабочие промышленности, строительства, работники просвещения, здравоохранения, а также работники учетно-плановых профессий. Спектр промышленных и строительных профессий весьма широк. Маятниковые мигранты работают электриками, электромонтерами, станочниками, штамповщиками, кузнецами, слесарями, малярами, штукатурами, столярами, плотниками, т.е. по тем профессиям, которые в перспективе должны занимать прочное место на селе по мере индустриализации сельского хозяйства и развертывания строительства предприятий и учреждений по обслуживанию населения [5]. Особенно велика доля мигрантов в промышленности деревообрабатывающей и целлюлозно-бумажной, строительных материалов, химической, машиностроения и металлообработке.

Сельские мигранты имеют и другие социальные характеристики. Поскольку это прежде всего молодежь, то среди них больше одиночек, чем у работающих на селе (18 против $11 \%)$. В семьях, работающих в городах, меньше число детей. Малодетность семей, работающих в городах, может быть фактором, позволяющим мигрантам работать в городах, поскольку у них больше свободного времени, чем у многодетных семей. Частично «погружение» в городской образ жизни, расширение круга потребностей и возможностей их удовлетворения, в том числе и повышенный уровень образования, отодвигают удовлетворение потребности в детях на второй план.
Социологами отмечено, что тесно связаны между собой такие черты индивида, как уровень образования и стремление повышать его: чем выше уровень образования, тем больше желание учиться дальше. Более высокая образовательная подготовка работающих в городах и в этом случае сочетается с большим удельным весом среди мигрантов, совмещающих работу с учебой (удельный вес этой категории работающих в городах выше в 2 раза и более по сравнению с работающими на селе). То обстоятельство, что одна треть учащихся из числа работающих в городах - это студенты заочных и вечерних высших и средних специальных учебных заведений, а еще одна треть из числа учащихся в городах намерена повысить свое образование в этих учебных заведениях, - еще одно свидетельство предпочтения маятниковыми мигрантами того социального блага, которого почти нет на селе. Отсюда социальная обусловленность маятниковой миграции в городах. Удовлетворить запросы сельской молодежи в среднем специальном и высшем образовании можно путем дальнейшего расширения заочного образования в вузах, техникумах и колледжах, организации консультативных и подготовительных курсов на селе, проведения выездных сессий в сельских районных центрах. Необходимо также расширить номенклатуру специальностей в колледжах и техникумах [6]. Дело в том, что в перспективе потребностей сельских предприятий в специалистах несельскохозяйственного профиля, особенно в сфере обслуживания населения, резко возрастут. Частичная подготовка их на селе может способствовать закреплению кадров.

Семьи маятниковых мигрантов, работающих в городах, характеризуются большим удельным весом не имеющих личного подсобного хозяйства: он в 3 раза больше, чем у работающих на селе. Правда, эта черта хозяйства вообще свойственна жителям пригородных поселений, поскольку среди них не так уж много работников, связанных с сельским хозяйством. Семьи маятниковых мигрантов в подавляющей части несельскохозяйственные. По данным выборочного обследования доля занятых в сельском хозяйстве во всем общественном хозяйстве пригородных поселений в области составила немного более одной пятой. Таким образом, для работающих в городах жителей пригородных поселений в целом характерно отсутствие личного подсобного хозяйства. Как оценить это явление? В условиях недо- 
статочного снабжения населения сел продуктами через торговую сеть всем жителям села целесообразно иметь подсобное хозяйство. К сожалению, многие сельские жители, особенно те, кто имеет высокий уровень образования и более широкий набор потребностей, предпочитают его не иметь. Более того, в отдельных случаях необходимость ведения подсобного хозяйства может послужить мотивом маятниковой миграции из села в город, что видно из таблицы, в которой приведена структура мотивов потенциальной маятниковой миграции.

По-видимому, для жителей сельских поселений ведение личного подсобного хозяйства за последние 10 лет стало нежелательным явлением, несмотря на снижение его трудоемкости, за счет помощи, оказываемой совхозами и колхозами. Особенно велика негативная оценка ведения подсобного сельского хозяйства у молодежи. Об этом свидетельствуют и данные бюджетов времени маятниковых мигрантов.

По структуре годового бюджета времени образ жизни маятникового мигранта - переходный от сельского к городскому. По сравнению с сельскими все работающие в городе маятниковые мигранты тратят на ведение личного подсобного хозяйства времени в 2 раза меньше. У маятникового мигранта на одну треть больше свободного времени, чем у сельского работника. Причем структура его прогрессивнее: они больше времени тратят на образование. Из-за того, что у них меньше детей и соответственно меньше затрат времени на уход за ними и воспитание, у работающих в городах сельских жителей остается больше времени на отдых и развлечения. Тем не менее их общая трудовая нагрузка несколько превышает нагрузку работающих горожан. Режим рабочего дня сельских жителей, работающих в городах, устойчив: каждые 8 из 10 мигрантов работают 7-8 ч в день, в то время как треть сельских работников имеет неустойчивый режим рабочего дня [7].

Дальше мы сделаем попытку детального анализа трудовых связей одного из сел Нижегородской агломерации - Линды. Особенностью географического положения села является его расположение на пересечении железной дороги с автомобильными магистралями, ведущими в города Нижний Новгород, Бор, Семенов, Городец, северную часть Борского района и ближайшие селения. При изучении маятниковых мигрантов было охвачено обследованием около 90\% всех выезжающих на работу в другие населенные пункты. В прошлом году маятниковые мигранты составляли около $50 \%$ всего трудоспособного населения. Преобладающее число маятниковых мигрантов направляется в города Нижегородской агломерации $(90,1 \%)$, особенно в ее ядро. Это обусловлено обширностью и разнообразием сфер приложения труда, и удобством транспортного сообщения. После Нижнего Новгорода стоит Бор, но его относительная доля невелика. Совсем небольшой процент выезжающих приходится на Городец. Анализ стажа работы показал, что поездки городецкого направления сохранились с тех пор, когда Линда входила в Городецкий район и связи с ним были более активными.

Структура мотивов потенциальной маятниковой миграции сельских жителей (\% к совокупности всех ответов)

\begin{tabular}{|l|c|c|}
\hline \multicolumn{1}{|c|}{ Мотивы } & 2008 & 2018 \\
\hline Неудовлетворенность сельским образом жизни или населенным пунктам в целом & 13,0 & 6,0 \\
\hline Тяжелая и неинтересная работа & 16,4 & 18,4 \\
\hline Низкая оплата труда & 6,8 & 2,3 \\
\hline Отсутствие детских учреждений, школ, специальных учебных заведений & 13,9 & 11,0 \\
\hline Желание жить с родственниками & 5,5 & 10,2 \\
\hline Не удовлетворяют природно-климатические условия, по состоянию здоровья & 5,1 & 8,1 \\
\hline Трудности с жильем и его благоустройством & 5,6 & 7,8 \\
\hline Трудности ведения личного подсобного хозяйства & 1,5 & 9,4 \\
\hline Плохая работа транспорта & 0,4 & 3,0 \\
\hline Плохое снабжение & 0,9 & 3,1 \\
\hline Неблагоприятный психологический климат: отсутствие анонимности, пьянство и другие & 4,2 & 9,5 \\
\hline Недостатки в бытовом обслуживании & 2,1 & 2,4 \\
\hline Плохое культурное обслуживание & 2,5 & 2,7 \\
\hline Не дали определенного ответа & 22,1 & 6,1 \\
\hline
\end{tabular}


За вычетом дистанционных рабочих доля выезжающих в Семенов составляет $2 \%$, что объясняется ограниченностью спроса на рабочие руки и в какой-то мере положением на «полюсе», противоположном основному направлению выезда. Заметна доля выезжающих в сельскую местность. Но пункты выезда рассредоточены, в каждом из них работает, как правило, 1-2 человека. Анализ половой структуры маятниковых мигрантов показал, что в выезде преобладают мужчины, их на 13,2\% больше, чем женщин. Это связано с развитием в селе сферы обслуживания, которая в основном использует женскую рабочую силу, и большей привязанностью женщин к домашнему и подсобному хозяйству. Среди выезжающих в Нижний Новгород, Семенов и Городец превышение доли мужчин близко к средним показателям. Для выезжающих в сельскую местность и Городецкий леспромхоз характерно резке преобладание мужчин (70\% и 90\% соответственно), поскольку в леспромхоз выезжают в основном лесорубы и шоферы, а в колхозы - механизаторы. Среди выезжающих в Борском направлении преобладают женщины, так как здесь загородники больше всего привлечены в сферу обслуживания. Превышение доли мужчин характерно не для всех возрастных групп. Оно наблюдается в возрастах старше 24 лет, за исключением 40-51 год, где преобладают женщины, и 51-53, где их доля одинакова. Снижение доли мужчин в младших возрастах, выезжающих обусловлено привлечением юношей для службы в армии и, вероятно, более длительной профессиональной подготовки, так как среди мужчин квалифицированных рабочих больше, чем среди женщин. В возрастах от 45 до 53 лет в селе наблюдается наиболее неблагоприятная половая структура, что отражается на структуре маятниковых мигрантов. Наиболее ярко выражен мужчин в возрасте 30-45 лет, поскольку многие женщины возрастной группы по семейным обстоятельствам вынуждены искать работу по месту жительства или не работать совсем. Оценка возрастного состава показывает, что самый незначительный объем выезжающих в возрасте $16-18$ лет $(0,6 \%)$ и старше 60 лет (1,5\%). Представители младшей возрастной группы выезжают только в Нижний Новгород, старшей - в Нижний Новгород и на Бор. Почти половину выезжающих составляют люди средних возрастов, это в значительной мере определяет их образовательный и квалификационный состав.
Вторая по величине группа - младшая, но значительна доля и старших возрастов. Следовательно, в трудовые связи вовлечены все возрастные слои населения, и маятниковые миграции являются неотъемлемой частью социально-экономического облика Линды. В браке состоят $83 \%$ выезжающих. Процент брачности зависит от пола и возраста. До 30 лет этот показатель у мужчин ниже, чем у женщин (соответственно 29\% и $59 \%$ в возрасте до 25 лет и $85 \%$ и $90 \%$ в группе от 26 до 30 лет). От 30 до 36 лет доля состоящих в браке одинакова - около $98 \%$, от 36 до 50 лет разница наиболее значительна: семейные мужчины составляют $98 \%$, а женщины - $69 \%$.

Высокий процент брачности в возрастах с благоприятной половой структурой показывает, что маятниковые миграции не оказывают отрицательного влияния на эту сторону демографической ситуации.

\section{Выводы}

Таким образом, маятниковая миграция охватывает все более значительные слои населения, возрастает ее роль в жизни общества. Сделана попытка изучения маятниковой миграции как современной черты сельского образа жизни. Нашли свое дальнейшее развитие социальные аспекты в изучении маятниковой миграции населения. Процессы формирования новых центров социально-экономического развития области и становления агломерации в окружении Нижнего Новгорода развиваются одновременно. Дальнейшее развитие маятниковой миграции во многом зависит от того, какому из этих процессов будет отдано предпочтение в перспективной организации территориально-хозяйственного комплекса города.

\section{Список литературы / References}

1. Аракчеева О.В., Кривдина И.Ю. Миграции населения Нижегородской области // Успехи современного естествознания. 2018. № 12-2. С. 339-344.

Arakcheeva O.V., Krivdina I.Yu. Migration of the population of the Nizhny Novgorod region. // Advances in current natural sciences. 2018. № 12-2. Р. 339-344 (in Russian).

2. Смирнова В.М. Маятниковые трудовые связи и семья / Под ред. Д.И. Валеттой. М.: Финансы и статистика, 1991. С. 62-70.

Smirnova V.M. Pendulum labor relations and family / Pod red. D.I. Valettoy. M.: Finansy i statistika, 1991. P. 62-70 (in Russian).

3. Михайлова Т.Е. Особенности маятниковой миграции в зонах влияния больших городов. М.: Веста, 2001. 247 с.

Mikhailova T E. Characteristics of circular migration in the zones of influence of large cities. M.: Vesta, 2001. 247 p. (in Russian).

4. Регионы России. Социально-экономические показатели. 2016 [Электронный ресурc] URL: http://www.gks.ru/ bgd/regl/B16_14p/Main.htm (дата обращения: 07.11.2019). 
Region of Russia. Socio-economic indicators. 2016 [Electronic resource] URL: http://www.gks.ru/bgd/regl/B16_14p/ Main.htm (date of access: 07.11.2019) (in Russian)

5. Бикмаева А.В., Лябина А.Н., Пухарев А.С. Маятниковая миграция населения между крупными городами Нижегородской области // Орфановские чтения - 2018: Всероссийская научно-практическая конференция. Нижегородский государственный педагогический университет имени Козьмы Минина 14 декабря 2018. Н. Новгород, 2019. С. 53-58.

Bikmaeva A.V., Labina A.N., Pujari A.S. Pendular migration between the major cities of the Nizhny Novgorod region // Orfanovskiye chteniya - 2018: Vserossiyskaya nauchno-prakticheskaya konferentsiya. Nizhegorodskiy gosudarstvennyy pedagogicheskiy universitet imeni Koz'my Minina 14 dekabrya 2018. N. Novgorod, 2019. P. 53-58 (in Russian).

6. Смирнова Ж.В., Красикова О.Г. Современные средства и технологии оценивания результатов обучения.
Вестник Мининского университета. 2018. Т. 6 № 3. [Электронный pecypc]. URL: https://vestnik.mininuniver.ru/ jour/article/view/870 (дата обращения: 14.12.2019). DOI: 10.26795/2307-1281-2018-6-3-9.

Smirnova J.V., Krasikova O.G. Modern tools and techniques of assessment of learning outcomes. Vestnik Mininskogo universiteta. 2018. V. 6. № 3. [Electronic resource]. URL: https://vestnik.mininuniver.ru/jour/article/view/870 (date of access: 14.12.2019) (in Russian).

7. Шевченко И.А., Соткина С.А., Голованева А.П., Макарова И.С., Бикмаева А.В. Маятниковая миграция сельского населения Нижегородской области // Успехи современного естествознания. 2019. № 1. С. 117-122.

Shevchenko I.A., Snatkina S.A., Golovanov A.P., Makarov I.S., Bikmaeva A. Circular migration of the rural population of the Nizhny Novgorod region // Advances in current natural sciences. 2019. № 1. P. 117-122 (in Russian). 